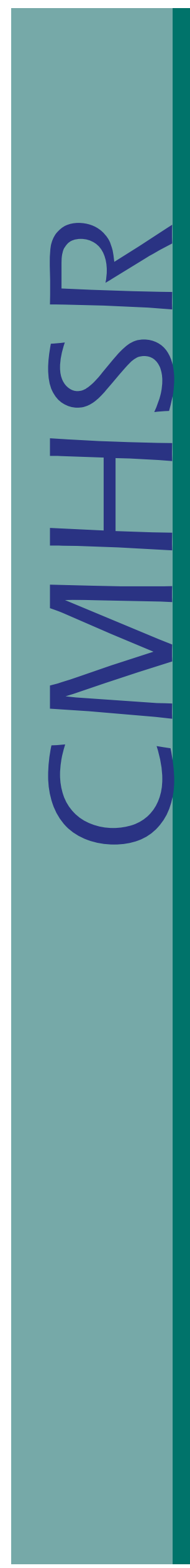

October 2005

Vol 2, Issue 8

\title{
Recent Research Findings from the Program for Clubhouse Research
}

Colleen McKay, M. A., C.A.G.S.

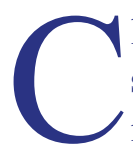
lubhouses believe that recovery from serious mental illness (SMI) must involve the whole person in a vital and culturally sensitive community within which members (adults with SMI) can receive the supports necessary to lead productive and satisfying lives. Members are involved in all operational aspects of the clubhouse, working side-by-side with staff. Clubhouses offer a range of services including vocational supports, community-based employment (Transitional, Supported, and Independent Employment), education, housing, outreach, advocacy, assistance with accessing health care, substance abuse services, as well as social and recreational opportunities.

The clubhouse model originated at Fountain House in New York City in 1948. Currently, 317 clubhouses in 27 countries are affiliated with the International Center for Clubhouse Development (ICCD). The ICCD maintains a set of clubhouse standards, a well documented training process, and a certification process. Two fidelity instruments 1,2 also exist to assess adherence to the clubhouse model.

The Program for Clubhouse Research (PCR) was established in 2000 to increase the quanitity and quality of research on the clubhouse model. This brief highlights findings from four research studies conducted by the PCR and its collaborators, examining employment outcomes, clubhouse costs, and wellness activities.

\section{Employment Outcomes}

Two studies focused on employment outcomes. The first study ${ }^{3}$, the Employment Intervention Demonstration Program (EIDP), was

C 2005 Center for Mental Health Services Research Department of Psychiatry University of Massachusetts Medical School a multi-site research study designed to evaluate different methods of enhancing employment outcomes for adults with SMI. An ICCD Clubhouse Program was compared to a Program of Assertive Community Treatment (PACT).

PACT programs provide professionally staffed, intensive, interdisciplinary, community-based services to adults with SMI in their homes or in the community.

PACT and clubhouse employment outcomes were compared for several types of employment. The analysis compared Transitional Employment (TE) jobs with other types of employment, including temporary jobs and/or jobs designated for individuals with a disability. Findings suggest:

- Individuals in clubhouse TE positions and in clubhouse non-temporary jobs had longer job tenures than individuals in PACT temporary non-TE jobs or non-temporary positions;

- Job tenure in clubhouse TE positions was longer than all employment types examined except for clubhouse non-temporary jobs; and

- Job earnings among clubhouse TEs and clubhouse non-temporary positions outpaced earnings in PACT temporary or non-temporary positions.

The second study ${ }^{4}$ examined employment outcomes of individuals at 17 clubhouses between 1998 and 2001. During this period, 1,702 individuals worked in 2,714 separate job placements in Transitional (TE), Supported (SE), and Independent Employment (IE) positions. Analyses indicate:

- Individuals with longer clubhouse memberships tended to work longer and had higher job earnings than individuals with shorter memberships;

- Members became employed as quickly as clubhouse and PACT participants in the Massachusetts EIDP $^{5}$ study; and

- The time to job (time between start of clubhouse 
membership to first job placement) in this sample is very similar to the time to job for all participants in the EIDP study from all supported employment models (6.4 months vs. 6.5 months $)^{6}$.

A third employment research study ${ }^{7}$ expanded upon findings from the second study mentioned above, examining employment transitions made by 2,195 clubhouse members that had 3,379 job placements in TE, SE, or IE over a four-year period. Results indicate:

- Clubhouse members utilized and moved between TE, SE, and IE in both directions; and

- Members who did not remain in the same job type were significantly more likely to move from employment types offering more supports (TE or SE) to those that offer less supports (SE or IE).

\section{Clubhouse Costs}

Costs of services ${ }^{8}$ were analyzed using data from a sample of ICCD clubhouses in 12 countries that responded to an International Survey of Clubhouses in 2000. Findings suggest:

- The mean cost per person per clubhouse visit was $\$ 27.12$;

- The annual cost per member was \$3,203.

The cost per member is similar to other studies. $5,9,10$ However, the clubhouse model appears to be less costly than other comparable service models, including some forms of supported employment. $5,9,11$

\section{Wellness Activities}

A final research study 12 evaluated the effectiveness of a structured physical exercise program in an ICCDcertified clubhouse. Seventeen clubhouse members completed a sixteen-week exercise program. Findings indicated:

- Significant improvement in members' aerobic capacity, and perceived mental health; and

- Positive trends in members' perceived improvements in physical and social functioning.

Participants expressed satisfaction with the program and noted the value of group support in adhering to the exercise program with quotes from some participants, including one individual who lost over 100 pounds.

\section{Future Research}

Historically, clubhouse-related research has been limited.

For more information regarding clubhouse research activities see http://iccd.org/base.asp?SectionID=7 or contact Colleen McKay at: colleen.mckay@umassmed.edu.
Findings from these research studies suggest that components within the clubhouse model have positive results, including increased employment, cost effectiveness and wellness. It will be important to conduct further studies which evaluate the effectiveness of other aspects of the clubhouse model.

Current research efforts within the Program for Clubhouse Research include: (1) a review of the evidence base for the clubhouse model; (2) developing a logic model for the clubhouse model; and (3) a comparison of 2-week vs. 3-week training on the clubhouse model for clubhouse staff and members.

\section{References}

1. Lucca, A. M. (2000). A clubhouse fidelity index: Preliminary reliability and validity results. Mental Health Services Research, 2, 89-94.

2. Macias, C., Propst, R.N., Rodican, C., \& Boyd, J. (2001). Strategic Planning for ICCD Clubhouse Implementation: Development of the Clubhouse Research and Evaluation Screening Survey (CRESS). Mental Health Services Research, 3, 155-167.

3. Johnsen, M., McKay, C., Henry, A., \& Manning, T. D. (2004). What does competitive employment mean? A secondary analysis of employment approaches in the Massachusetts Employment Intervention Demonstration Project. In W. Fisher (Ed.) Employment for Persons with Severe Mental Illness, Volume 13, Research in Community and Mental Health. Oxford, UK: Elsevier.

4. McKay, C., Johnsen, M., \& Stein, R. (2005). Employment outcomes in Massachusetts clubhouses. Psychiatric Rehabilitation Journal, 29 (1), 25-33.

5. Macias, C. (4-16-2001). Final Report: Massachusetts Employment Intervention Demonstration Project. "An Experimental Comparison of PACT and Clubhouse". Cooperative Agreement No. SM 51831, 1-36. 6. Cook, J. (2001, January 8). Characteristics of EIDP Participants and the Jobs They Hold: Preliminary Findings of the Employment Intervention Demonstration Program (EIDP). Retrieved September 7, 2005, from http://www.psych.uic.edu/eidp/eidpcharacteristics.pdf. 7. McKay, C., Johnsen, M., Banks, S., \& Stein, R. (in press). Employment transitions for members of Massachusetts clubhouses. Work: A Journal of Prevention, Assessment, and Rehabilitation. 8. McKay, C., Yates, B., \& Johnsen, M. (in press). Costs of clubhouses: An international perspective. Administration and Policy in Mental Health and Mental Health Services Research.

9. Cowell, A., Pollio, D.E., North, C.S., Stewart, A.M., McCabe, M.M., \& Anderson, D.W. (2003). Deriving Service Costs for a Clubhouse Psychosocial Rehabilitation Program. Administration and Policy in Mental Health, 30, 323-340.

10. Macias, C., Barreira, P., Alden, M., \& Boyd, J. (2001). The ICCD benchmarks for clubhouses: A practical approach to quality improvement in psychiatric rehabilitation. Psychiatric Services 52, 207-213.

11. Clark, R. E., Xie, H., Becker, D. R., \& Drake, R. E. (1998). Benefits and costs of supported employment from three perspectives. Journal of Behavioral Health Services \& Research, 25, 22-34. 12. Pelletier, J., Ngyuen, M., Bradley, K., Johnsen, M., \& McKay, C. (in press). Integrating structured physical exercise into an ICCD certified clubhouse program: Results of a pilot study. Psychiatric Rehabilitation Journal.

Visit us on-line at www.umassmed.edu/cmhsr 